\title{
Micromechanical modeling of tension stiffening in FRP-strengthened concrete elements
}

\author{
Bahman Ghiassi ${ }^{1 a}$, Masoud Soltani ${ }^{*}$, Sara Rahnamaye Sepehr ${ }^{2}$ \\ ${ }^{I}$ Microlab, Faculty of Civil Engineering and Geosciences, Delft University of Technology, Delft, The \\ Netherlands \\ ${ }^{2}$ Faculty of Civil and Environmental Engineering, Tarbiat Modares University, Tehran, Iran
}

\begin{abstract}
This paper presents a micro-modeling computational framework for simulating the tensile response and tension stiffening behavior of FRP-strengthened RC elements. The total response of strengthened elements is computed based on the local stress transfer mechanisms at the crack plane including concrete bridging stress, reinforcing bars stress, FRP stress and the bond stresses at the bars-to-concrete and FRP-to-concrete interfaces. The developed model provides the possibility of calculating the average response of FRP, reinforcing bars and concrete as well as the crack spacing and crack widths. The model, after validation with experimental results, is used for a systematic parameter study and development of micromechanics-based relations for calculating the crack spacing, FRP critical ratio, debonding strength and effective bond length. Constitutive models are also proposed for concrete tension stiffening and average response of steel reinforcing bars in FRPstrengthened members as the main inputs of smeared crack modeling approaches.
\end{abstract}

Keywords: FRP; concrete; tension stiffening; smeared crack; micromechanics; local stress field approach.

*Corresponding author: Associate Professor, E-mail: soltani@modares.ac.ir.

${ }^{a} \mathrm{PhD}$, Marie Curie IF Research associate E-mail: bahmanghiassi@gmail.com, B.Ghiassi@tudelft.nl 


\section{Introduction}

Externally Bonded Reinforcement (EBR) with Fiber Reinforced Polymers (FRPs) has been extensively used as an effective technique for seismic performance improvement or durability enhancement of concrete infrastructure. Extensive experimental, analytical and numerical studies have shown the effectiveness of this technique in improving the strength and stiffness of RC elements. Although the effect of FRP application and FRP-concrete bond on the ultimate limit state (ULS) behavior of strengthened elements have been extensively studied [1,2], their effect on the service limit state (SLS) behavior and cracking has received less attention [3-7].

The available experimental studies on cracking response of FRP-strengthened RC elements are still limited and mostly focused on cracking behavior of RC beams. The available results show FRP application affects the stiffness and deformation of the strengthened elements and leads to reduction of crack spacing and width $[5,8]$. The analytical and numerical investigations on this subject are also still limited $[3,7,9,10]$ and comprehensive models describing the tension stiffening with detailed consideration of micromechanical mechanisms are scarce. As for macro-modeling, suitable constitutive models, as the main inputs of smeared crack modeling approaches, are not available yet. In a recent study, Yang et al. [11] addressed this issue by proposing new formulations, based on theoretical and experimental analysis, for calculating the Poisson's ratio and the softening coefficient in FRP-strengthened RC elements. The average steel and FRP response in FRP-strengthened concrete elements, however, still remain unaddressed.

Prediction of the cracking behavior is a complicated task and, even though that have been extensively studied for several years, is still an open issue in the mechanics of RC components. Several models have been proposed for modeling the average tensile behavior of reinforcing bars and concrete in RC elements [12-17], while the number of recent studies on this subject shows 
there are still debates on the accuracy of the previous models [4,18-21]. Most of the available formulations for prediction of the crack spacing and width have been found to produce controversial results depending on the geometry of the specimens and reinforcement type [21]. A universal model applicable for a wide range of $\mathrm{RC}$ elements and geometries is therefore still lacking [20]. In case of FRP-strengthened concrete, considering the involved uncertainties and the differences in nonlinear mechanics of RC and FRP-RC elements, the available models for RC elements can be used as a starting point. These differences include different geometrical and mechanical properties of FRPs compared to reinforcing bars (FRPs show an elastic response with a brittle failure at ultimate stress state). Additionally, in contrast to the reinforcing bars, FRP debonding usually occurs independent from the FRP anchorage length [22].

This paper presents a computational framework for simulating the tensile response of FRPstrengthened concrete elements based on the local stress field approach [23]. The model considers all the local stress transfer mechanisms at the crack plane (in concrete, reinforcing bars and FRP sheets and the bond stresses) and the interactions between them through compatibility equations. The main outputs of the model are the crack distribution and width, the contribution of different mechanisms in the total response of the strengthened element, the average response of FRP and reinforcing bars, and the concrete tension stiffening behavior.

The developed model, after validation with experimental results, is used for performing a systematic parameter study and deep investigation of the tensile response of FRP-strengthened RC members. This led to proposal of micromechanics-based formulas for crack spacing, FRP debonding strength, FRP critical ratio, and effective bond length as well as proposal of constitutive models for average response of steel and FRP and for tension stiffening of concrete. The proposed 
models are then used as the input of numerical models for simulating the nonlinear response of two FRP-strengthened RC beams using smeared crack modeling approach.

\section{Mechanics of cracked FRP-strengthened RC tensile members}

Once a FRP-strengthened RC element cracks, the reinforcing bars and FRP sheets become activated and contribute to the transmission of stresses along the element. The state of stresses in a cracked element can be presented based on local stresses at the crack plane or average stresses over the entire element as shown in Fig. 1. Note that it is assumed that the reinforcing bars and FRP sheets are placed in a uniform and smeared configuration with reinforcement ratio of $\rho_{s x}$ and $\rho_{F R P}$, respectively. As only tensile elements are considered here, no shear stresses exist at the crack plane and the crack direction is normal to the tensile stresses.

Reinforcing bars, FRP sheets and concrete bridging stress carry the local stresses at the crack plane $[24,25]$. The interlocking between the crack surfaces results in transmission of some residual tensile stresses along the cracked planes. On the other hand, the stresses developed in reinforcing bars and FRP sheets are partly transferred to the concrete between adjacent cracks owing to the bond stresses at reinforcing bars-concrete and FRP-concrete interfaces, see Fig. 2. The concrete tensile stress at the crack plane does not thus drop to zero and shows a tension softening behavior $[4,24]$. The concrete tension softening, in comparison to the bond stresses transferred to concrete, is negligible in RC elements with ordinary reinforcement ratio [23]. However, it can have a large contribution in the tensile response of lightly reinforced concrete elements and therefore cannot be neglected [12].

With increasing the stresses, the reinforcing bars yield at the crack plane before the embedded bars between two adjacent cracks. This is followed by hardening of reinforcing bars after yielding while the other parts may be still in the elastic zone. As a result, the bars' average stress over the entire 
element become lower than the bare bars. In case of FRP sheets, the stress can theoretically increase until FRP rupture although FRP delamination usually governs the behavior [4,9]. The stresses are again higher at the cracked planes in comparison to other locations along the element and the average stresses are lower in comparison to bare conditions.

The computational framework developed in this study considers all the above-mentioned mechanisms to simulate the nonlinear tensile response of FRP-strengthened concrete elements.

\section{Constitutive laws}

The adopted constitutive laws are presented and discussed in this section. For the cracked concrete, the bridging stress model proposed by Ushida et al. [26] is used. The FRP tensile behavior is assumed linear elastic until rupture. The steel reinforcement is assumed to be linear until yielding followed by plasticity and strain hardening. The bond behavior between reinforcement and concrete is simulated using the bond-slip-strain model proposed in Shima et al. [27]. The effect of bond deterioration due to splitting and cracking of the concrete is also integrated in this model. For the bond behavior at FRP-concrete interface, the nonlinear bond stress-slip relation proposed by Nakaba et al. [28] is used. A brief description of each constitutive law is given next.

\subsection{Concrete bridging stress}

Various linear [29], bilinear [30-32] and exponential models [33] have been proposed in the literature for modeling the bridging stresses in concrete [29]. The nonlinear concrete bridging stress model proposed by Ushida et al. [26] is selected and used in this study. This model is defined by three parameters namely the concrete tensile strength, $f_{\mathrm{t}}$, the crack width, $w$, and the fracture energy of plain concrete, $G_{\mathrm{f}}[26]$ :

$$
\sigma_{b r}=f_{t}\left[1+0.5\left(\frac{f_{t}}{G_{f}}\right) w\right]^{-3}
$$


The crack width is obtained as $\left(\varepsilon_{1}-\varepsilon_{\mathrm{cr}}\right) \times$ crack spacing, where $\varepsilon_{1}$ is the concrete total tensile strain and $\varepsilon_{\mathrm{cr}}$ is the concrete cracking strain. As for the fracture energy, $G_{\mathrm{f}}$, a wide range of analytical formulations have been proposed in the literature for calculation of this parameter see e.g. Table 1. This parameter has been presented as a function of compressive strength and maximum aggregate size in some cases, [34,35], and its dependency on the water to cement ratio is also considered [36]. CEB-FIP 2010 [37], on the other hand, has considered this parameter as the function of compressive strength only. A comparison between these models, Fig. 3, shows that the predictions vary significantly for a wide range of concrete properties. Although investigation of the accuracy of these models is out of the scope of the presented study, the effect of variation of fracture energy on the tension stiffening behavior of FRP-strengthened RC elements is discussed in Sec. 5.

\subsection{Local stress transfer along reinforcing bars}

The reinforcing bars-to-concrete bond behavior has been the subject of several numerical, analytical and experimental investigations in the literature. Different constitutive laws ranging from simple average bond-slip models to more sophisticated models that account for the effect of stress level, confinement, and concrete cracking have been proposed [38-42]. The bond-slip-strain model proposed in Shima et al. [27] is selected in this study for the simulations. This model takes into account the effects of reinforcement diameter, elasticity, strain hardening and stiffness in strain hardening zone and has been extensively used in the literature [23,43]. This model is also among the few available models that is applicable for both elastic and post-yield ranges of the reinforcement behavior. The bond stress in this model is presented as:

$$
\begin{aligned}
& \tau(\varepsilon, s)=\tau_{0}(s) \cdot g(\varepsilon) \\
& \tau_{0}(s)=0.73 f_{c}^{\prime}[\operatorname{Ln}(1+5 s)]^{3}
\end{aligned}
$$


$g(\varepsilon)=\frac{1}{1+10^{5} \varepsilon}$

where $\tau_{\mathrm{o}}(\mathrm{s})$ is the intrinsic bond stress when strain is zero, $f^{\prime}$ is the concrete compressive strength, $\varepsilon$ is the bar strain, $s$ is a non-dimensional slip equal to $1000 S / d, d$ is the bar diameter and $S$ is the slip which is computed by integrating over the length of the bar starting from the center line between two adjacent cracks, see Fig. 4. Eq. (4) controls the reduction of bond stress in the post yielding range. As presented in Fig. 4, by yielding of reinforcing bars at the vicinity of the crack plane, the bar strain suddenly increases to the strain hardening zone leading to a drop of the local bond stress in the plastic region [23].

It is known that the bond performance near the crack plane may deteriorate due to splitting and crushing of the concrete around the bars [44]. This effect is accounted here based on the model developed by Shin [45] and Qureshi and Maekawa [46]. In this model, the bond deterioration zone is equal to $5 d$ from the crack surface and has the following pattern, see Fig. 5:

$$
\begin{array}{lr}
\tau(x)=\tau_{\max }-\frac{\tau_{\max }}{L_{b}}\left[x-\left(\frac{L_{c}}{2}-L_{b}\right)\right] & \frac{L_{c}}{2}-L_{b} \leq x \leq \frac{L_{c}}{2}-\frac{L_{b}}{2} \\
\tau(x)=0 & \frac{L_{c}}{2}-\frac{L_{b}}{2} \leq x \leq \frac{L_{c}}{2}
\end{array}
$$

For any given average bar strain and length of reinforcing bar between two adjacent cracks, the stress and strain profile along the element can be computed based on the bond stress distribution along the reinforcement. The reinforcing bar is initially divided into finite segments. The bond stress and slip at the midway between two adjacent cracks are zero, acting as the boundary conditions for the first segment, see Fig. 6. Satisfying the equilibrium conditions on a small segment along the bar, the following equilibrium equation is derived:

$\frac{d \sigma_{s}}{d x}=\frac{\pi d}{A_{s}} \overline{\tau_{s}}$ 
where $d \sigma_{\mathrm{s}} / d x$ is the gradient of steel stress along the bar, $d$ and $A_{\mathrm{s}}$ are the diameter and the cross section area of reinforcing bars respectively and $\bar{\tau}_{s}$ is the average bond stress along the segment. Assuming the strain value at the middle of the two adjacent cracks, the stress and strain profiles can be computed by solving the equilibrium and slip compatibility equations, segment by segment along the reinforcing bar. An iterative procedure is necessary for each segment until the equilibrium condition is satisfied. The flowchart of the computational procedure is presented in Fig. 7. Starting from the first segment at midway between two adjacent cracks and assuming a strain increment, the stress and the slip at the other side of the segment and consequently the bond stress, are computed. The assumed strain increment is updated following an iterative procedure until the obtained stresses satisfy the equilibrium conditions. The computed strain and slip for the first segment will be the boundary condition for the next segment. This procedure is followed to obtain the stress and strain profile along the reinforcing bar. The details of the computational procedure is comprehensively presented in Soltani et al. [23].

\subsection{Local stress transfer along FRP}

Several bond-slip models have been proposed in the literature for modeling the bond behavior between FRP sheets and concrete elements [28,47-49]. The nonlinear bond stress-slip relation proposed by Nakaba et al. [28] is adopted here:

$\frac{\tau_{b F}}{\tau_{b F y}}=\frac{S_{F}}{S_{F y}} \cdot \frac{3}{2+\left(S_{F} / S_{F y}\right)^{3}}$

where $\tau_{\mathrm{bFy}}$ is the maximum local bond stress, $\tau_{\mathrm{bF}}$ is the bond stress, $S_{\mathrm{Fy}}$ is the slip at $\tau_{\mathrm{bFy}}$, and $S_{\mathrm{F}}$ is the slip at $\tau_{\text {bF. }}$. From a series of experimental results, Nakaba et al. [28] proposed 3.5f ${ }^{\prime}{ }^{0.19}(\mathrm{MPa})$ and $0.065(\mathrm{~mm})$ for the $\tau_{\mathrm{bFy}}$ and $S_{\mathrm{Fy}}$, respectively. In another study, these parameters are related to the concrete fracture energy as follows [5]: 
$\tau_{b F y}=6.6 \sqrt{G_{f F}} \quad(\mathrm{MPa})$

$S_{F y}=0.057 \sqrt{G_{f F}} \quad(\mathrm{MPa})$

where $G_{f \mathrm{~F}}$ is the fracture energy of the bonded area (in N/mm) and can be obtained from the debonding tests $[50,51]$.

The stress-strain profile along the FRP sheet can be obtained following a similar procedure as the reinforcing bars. Satisfying the equilibrium conditions on a small segment along the FRP sheet, the following equilibrium equation is derived:

$\frac{d \sigma_{F}}{d x}=\frac{\bar{\tau}_{F}}{t_{F}}$

where $d \sigma_{\mathrm{F}} / d \mathrm{x}$ is the gradient of FRP stress along the sheet, $t_{\mathrm{F}}$ is the FRP thickness, and $\bar{\tau}_{F}$ is the average bond stress along the segment. Starting from the first segment at midway between two adjacent cracks and assuming a strain increment, the stress and slip value at the other side of the segment and consequently the bond stress, are computed. As the boundary conditions for the first finite segment, the bond stress and slip at the midway between two adjacent cracks are zero. An iterative procedure is used in each segment until the equilibrium condition is satisfied. The flowchart for solving the bond-governing equations along the FRP sheet is shown in Fig. 8. It should be noted that the slip in the FRP sheet is calculated relative to the concrete substrate. In other words, the concrete deformation is subtracted from the FRP slip in each step of the analysis.

\section{Computational procedure}

The equilibrium of average stresses in tensile members can be expressed as:

$\tilde{\sigma}_{x}=\tilde{\sigma}_{C x}+\tilde{\sigma}_{S x}+\tilde{\sigma}_{F R P x}$

where, $\tilde{\sigma}_{F R P x} \tilde{\sigma}_{S x}, \tilde{\sigma}_{C x}$ are the stresses in concrete, reinforcing bars, and FRP sheets, respectively. The cracks are perpendicular to the element axis and therefore the concrete contribution is only 
limited to the bridging stresses at the crack plane. Investigating the effect of shear stresses at the crack plane in FRP-strengthened RC elements has been presented and discussed elsewhere, see [25]. Considering a unidirectional RC element, the contribution of reinforcing bars can be expressed as $\tilde{\sigma}_{S x}=\rho_{s x} \bar{\sigma}_{s x}$ where, $\rho_{s x}$ is the longitudinal reinforcement ratio and $\bar{\sigma}_{s x}$ is the spatial average stress of reinforcement along its axis. Similarly, the contribution of FRP can be expressed as $\tilde{\sigma}_{F R P x}=\rho_{F x} \bar{\sigma}_{F x}$ where, $\rho_{F x}$ is the longitudinal reinforcement ratio and $\bar{\sigma}_{F x}$ is the spatial average stress of FRP along its axis. The equilibrium of the local and average stresses in RC domain gives: $\sigma_{1}=\sigma_{b r}+\rho_{s x}\left(\sigma_{s x}^{c r}-\bar{\sigma}_{s x}\right)+\rho_{F x}\left(\sigma_{F x}^{c r}-\bar{\sigma}_{F x}\right)$

where $\sigma_{s x}^{c r}$ and $\sigma_{F x}^{c r}$ are the steel and the FRP local stresses at crack plane, respectively. Based on the compatibility relationships, the strains in the longitudinal direction ( $\mathrm{x}-\mathrm{y}$ coordinate system) can be expressed [25,52].

The computational procedure for simulating the total tensile response of elements can be summarized as follows, see Fig. 9. It is initially assumed that the element is not cracked ( $n=0, n$ is number of cracks) and the average spacing between cracks is therefore equal to the element length $\left(L_{\mathrm{c}}=L\right)$. The following steps are then taken for the analysis: (1) An average strain in the element is assumed; (2) The average spacing between cracks is calculated, $\mathrm{L}_{\mathrm{c}}=\mathrm{L} /(1+\mathrm{n})$; (3) The local and average strain and stress profile of the reinforcing bars along the element are calculated through an iterative procedure until the average strain in the reinforcing bar is equal to the assumed average strain in step 1. The iterative procedure and computational steps for this part are based on the flowchart presented in Fig. 7; (4) The local and average FRP strain and stress profiles along the element are calculated through an iterative procedure until having the average strain in the FRP sheet equal to the assumed average strain in step 1 . The iterative procedure and computational steps for this part are based on the flowchart presented in Fig. 8; (5) The average and local stresses 
in concrete are calculated. If the local tensile stress in concrete is less than its tensile strength, the element is not cracked and the computation is continued by going back to step 1 and increasing the assumed average strain. If the local tensile stress in concrete becomes larger than its tensile strength, the element is cracked and therefore the number of cracks (n) is updated; (6) The maximum stress in steel and FRP sheet are checked. If the maximum stress exceeds their corresponding strength, the failure is occurred. If failure occurs in both steel and FRP, the procedure will be terminated. Otherwise, the procedure is continued from step 1 by assuming a larger average strain. The modified Newton-Raphson method is used here for iterative solving the nonlinear equations.

\section{Model validation and exploitation}

The accuracy of the proposed model is investigated in this section by comparison of the analysis results with experimental tests performed by Ceroni et al. [6]. The tests consisted of direct tensile tests on GFRP and CFRP strengthened RC ties for investigating their cracking and tension stiffening behavior. The material properties and strengthening details of the specimens are presented in Table 3.

The main inputs of the developed program are materials properties (presented in Table 3), concrete fracture energy, and FRP-to-concrete bond properties. The FRP-concrete bond properties are dependent on several factors including the bond quality and mechanical properties of the FRP and the substrate. If the bond fracture energy, $G_{\mathrm{fF}}$, is available from debonding tests, Eqs. (9-10) can be used for calculation of these parameters. In the case of the selected experimental results, as such information are not available, a calibration of the bond-slip law parameters is necessary [7]. Ceroni et al. [7] performed a parametric study on the effect of bond parameters on the tensile response of FRP-strengthened concrete components. They observed that increment of the bond strength, $\tau_{\max }$, 
causes a stiffer behavior before steel yielding and a higher yielding load. On the other hand, a reduction of maximum slip, $s_{\max }$, leads to a less stiff behavior after yielding, and increasing the slip corresponding to the bond strength leads to a larger deformation before reinforcement yielding.

Although a different bond-slip law is used here, the results obtained from the developed computational framework confirm observations reported in Ceroni et al. [7]. As an example, the effect of bond strength, $\tau_{b F y}$, on the tensile response of TP1-C1 specimens is shown in Fig. 10 (a). It can be observed that increasing the $\tau_{b F y}$ leads to increment of pre-yield stiffness and the yielding load in the specimen response. The local stresses in FRP sheet and the bond stresses at FRPconcrete interface along the element are also presented in Fig. 10 (b) for the case of specimen TP1$\mathrm{C} 1$ with $\tau_{b F y}=4.5 \mathrm{MPa}$. It can be observed that the bond stresses reach the softening range with load increment. This is an evidence of initiation of FRP delamination and can be captured with the developed framework. The calibration results showed that the $\tau_{b F y}=3.0 \mathrm{MPa}$ and $S_{F y}=$ $0.05 \mathrm{~mm}$ produce the most accurate results, as also suggested in [7]. For this reason, these values are used for simulation of the tensile response of the next beams.

The fracture energy of plain concrete is assumed to be $0.15 \mathrm{~N} / \mathrm{mm}$ for all the cases as suggested in [53]. As it was shown in Fig. 3 there is a large variation in the fracture energy of plain concrete when different models are utilized. This variation is in the range of $0.05-0.15 \mathrm{~N} / \mathrm{mm}$ for the normal strength concrete, (a range of 0.1 to 0.15 is suggested in [53]). The results from the numerical analysis, however, show that the effect of fracture energy on the tension stiffening response of FRP-strengthened beams with a normal strength and reinforcement ratio more than the critical ratio is negligible, see Fig. 11. The assumption of fracture energy as $0.15 \mathrm{~N} / \mathrm{mm}$ therefore seems reasonable in the presented simulations. 
The behavior of four specimens is simulated with the developed computational model and the results are presented in Fig. 12. Reasonable agreement is found between the analytical and experimental results in terms of specimens' stiffness and behavior in the pre- and post-yield range of the reinforcement. The yielding point of the reinforcement has also been accurately predicted.

The developed computational model simulates the average tensile response of strengthened specimens based on the local stress transfer mechanisms at the crack plane and thus the contribution of each component (concrete, steel and FRP) in the total tensile behavior can be monitored. It should be noted that the observed difference in the initial stiffness of the numerical results and experimental curves is due to the fact that the specimens were preloaded until cracking before performing the tension stiffening tests. Additionally, the experimental tests were aborted when FRP debonding occurred in the specimens and therefore the ultimate capacity of the beams were not reached during the tests. This latter is the reason for the observed differences in the ultimate load of the specimens in experimental and numerical simulations.

The evolution of cracks along the element and thus the crack spacing can also be analytically obtained, see Fig. 13. The presented tension stiffening curve, for specimen TP-C1, clearly shows the crack development in the specimen. It can be observed that with formation of each crack in the element, the tension stiffening curve shows a local drop. Upon reaching a certain tensile strain, the cracks stabilize and no more cracks occur in the specimen. The average response of steel and FRP sheets can also be obtained with the aim of the developed program as in Fig. 13(a) for specimen TP-C1.

\section{Micromechanics-based design relations}

A systematic parameter study is performed in this section to investigate the effect of different parameters on crack spacing, critical reinforcement ratio, FRP debonding strength and effective 
bond length. Based on the performed parameter study, micromechanics-based relations are extracted and proposed for each mechanism in in FRP-strengthened RC elements. When possible, the proposed formulas are compared with the formulas available in the codes or literature to evaluate the accuracy of the derived relations in the present study. Quantitative evaluation of the accuracy of the derived formulas in predicting the available experimental results will, however, presented in future studies.

\subsection{Crack spacing}

For obtaining the crack spacing in FRP-strengthened RC elements, the crack spacing in RC elements is combined with the crack spacing in FRP-strengthened plain concrete elements as proposed in [25]:

$$
S_{\eta}^{1.5}=\frac{1}{\left(\frac{1}{S_{F}}\right)^{1.5}+\left(\frac{1}{S_{s}}\right)^{1.5}}
$$

where $S_{\eta}$ is the crack spacing in FRP strengthened RC element (in mm), $S_{\mathrm{F}}$ is the crack spacing in FRP-strengthened plain concrete and $S_{\mathrm{s}}$ is the crack spacing in RC element (in $\mathrm{mm}$ ).

Prediction of crack spacing in RC elements has been the subject of several studies in the literature [12,18-21,54-57]. A number of empirical, semi-empirical and theoretical models (based on stress transfer at the bar-to-concrete interface) have been proposed to calculate the stabilized crack spacing in these elements, see Table 2 as some examples. There has been several discussions on the accuracy of these models in prediction of crack spacing in structural components that is out of the scope of the current study. In this study, the model proposed by Salem [12] is used as it is among the most comprehensive ones and it considers the effect of reinforcement ratio, steel yield strength, concrete compressive and tensile strength and bar diameter. 
As for the FRP-strengthened plain concrete, a formulation is proposed based on a parametric study performed with the aim of the developed computational framework. It is assumed that the crack spacing is a function of concrete tensile strength, $f_{t}$, FRP width, $B_{F}$, FRP thickness, $t_{F}$, FRP ratio, $\rho_{F}$, FRP bond strength, $\tau_{\max }$, and FRP elastic modulus, $E_{F}$ :

$S_{F}=S_{0} \times k_{f_{t}} \times k_{A_{c}} \times k_{t_{F}} \times k_{E_{F}} \times k_{B_{F}} \times k_{\tau_{\max }}$

where $S_{0}$ is the reference crack spacing and is numerically obtained for an element with $B_{\mathrm{F}}=200 \mathrm{~mm}, E_{\mathrm{F}}=1 \mathrm{GPa}, t_{\mathrm{F}}=0.01 \mathrm{~mm}, t_{\mathrm{max}}=4 \mathrm{MPa}, A_{\mathrm{c}}=5000 \mathrm{~mm}^{2}, f_{\mathrm{t}}=2 \mathrm{MPa}$. The effect of each parameter on the crack spacing is then investigated (by changing that parameter and numerically obtaining the crack spacing) and the obtained results are presented in Fig. 14. With the aim of a regression analysis, the variation of crack spacing with respect to variation of each of these parameters is formulated and normalized to the reference crack spacing. Substituting the obtained relations in Eq. (15) leads to the following relation:

$S_{F}=\frac{1.14 \times f_{t}^{2.3} \times B_{F}^{0.2} \times t_{F}^{1.5}}{\rho_{F}^{1.7} \times \tau_{\max }^{2} \times E_{F}^{0.2}}$

\subsection{FRP critical ratio}

If a plain concrete element is strengthened with a reinforcement ratio less than a critical value, called FRP critical ratio, only one crack occurs in the strengthened element under tensile loading and therefore the concrete does not show a tension stiffening behavior. In other words, the concrete shows a tension stiffening behavior only when the reinforcement ratio is more than the FRP critical ratio. This ratio can thus be used as an indicative limit for using tension stiffening models for FRPstrengthened plain concrete elements in the smeared crack modeling approaches.

A parameter study is conducted here on the effect of different parameters on the FRP critical ratio. It is assumed that the FRP critical ratio is a function of bond strength, $\tau_{\max }$, concrete tensile strength, 
$f_{\mathrm{t}}$, concrete cross-section area, $A_{\mathrm{c}}$, FRP width, $B_{\mathrm{F}}$, and FRP elastic modulus, $E_{\mathrm{F}}$. The results are presented in Fig. 15 in terms of FRP sheet thickness (chosen as representative of the FRP critical ratio in unreinforced concrete elements). A similar approach as presented in the last section is followed for obtaining the correlation of these parameters with the FRP critical ratio. In this case, for obtaining the critical FRP ratio in a given strengthened beam, each of the above-mentioned parameters was reduced until occurrence of only one crack in the strengthened element. As an example, the procedure followed for obtaining the bond strength that leads to having FRP critical ratio in a given element is presented in Fig. 16. It can be seen that the bond strength of $3 \mathrm{MPa}$ led to occurrence of seven cracks in the element, while only two cracks occurred when the bond strength is reduced to 2.7 MPa. Finally, only one crack has occurred in the element when the bond strength is reduced to 2.6 MPa. The 2.6 MPa is thus chosen as the bond strength that leads to having FRP critical ratio in the selected element and represents one point in the graph presented in Fig. 15. The results of the conducted study led to the following relation:

$t_{F}=\frac{17550}{\tau_{\max }^{2} \times B_{F}^{2} \times E_{F}} \times A_{c}^{2} \times f_{t}^{2}$

This relation can be rewritten as follows:

$$
\rho_{c r-F}=\frac{t_{F} \times B_{F}}{A_{c}}=\frac{f_{t}}{0.24 \times \tau_{\max } \times \sqrt{\frac{E_{F}}{t_{F}}}}
$$

where, $\rho_{c r-F}$ is the critical FRP ratio, $t_{F}$ is the FRP thickness, $B_{F}$ is the FRP width, $E_{F}$ is the FRP modulus of elasticity, $A_{c}$ is the concrete area, and $\tau_{\max }$ is the maximum bond stress. 
This relation presents at interesting physical phenomenon. A strengthened element does not crack when the transferred stresses from FRP are less than the concrete tensile strength. At the limit state, in which one crack occurs (at FRP critical ratio), the following equilibrium can be written:

$$
f_{t} A_{c}=f_{f} A_{f}
$$

Combination of Eq. 18 and Eq. 19 gives:

$\rho_{c r-F}=\frac{A_{f}}{A_{c}}=\frac{f_{t}}{f_{f}} \rightarrow f_{f}=0.24 \times \tau_{\max } \times \sqrt{\frac{E_{F}}{t_{F}}}$

where, $f_{f}$ is the maximum FRP stress at the crack plane. Therefore, the FRP stress at the crack plane reaches this value, Eq. 20, when no more cracks occur in the element. In cases in which a strong bond exists between FRP and concrete, the FRP stress, $f_{f}$, can increase up to the FRP rupture stress $\left(F_{\mathrm{UF}}\right)$. Therefore, a more appropriate presentation of Eq. 20 can be as follows:

$$
f_{f}=\min \left(F_{U F}, 0.24 \tau_{\max } \sqrt{\frac{E_{F}}{t_{F}}}\right)
$$

Eq. 19 can also be written for reinforced concrete elements strengthened with FRP sheets as:

$$
f_{t} A_{c}=f_{f} A_{f}+f_{y} A_{s}
$$

\subsection{FRP debonding strength}

According to Eq. 21, the FRP stress can increase until the FRP rupture strength. However, FRP debonding usually occurs at much lower stress levels. When debonding occurs, crack localization occurs in the plain concrete at the debonded region. No additional cracks can thus be developed in the element, acting as concrete with FRP critical ratio. The FRP stress in this section and FRP debonding strength are thus equal to $f_{\mathrm{f}}$ in Eq. 20 . 
The obtained numerical results showed that even after reaching the softening branch of the bondslip curve, after $\tau_{\max }$, the FRP stress can still slightly increase if the FRP bonded length is larger than the effective bond length. This increase is in the range of 10-15\% if FRP strengthening ratio is less than the critical ratio. The debonding stress can thus be modified as follows (in average by 12.5\% increase in Eq. 18) for plain concrete elements strengthened with FRP (strengthening ratio<critical ratio):

$f_{d b}=0.27 \tau_{\max } \sqrt{\frac{E_{F}}{t_{F}}}$

when FRP bonded length is longer than the effective bond length or mechanical anchorage is used, and if the FRP reinforcement ratio is larger than the critical ratio, several cracks occur in the concrete element until the element reaches a stable condition and no more cracks occur. After the cracks are stabilized, the bond profile changes in the element. In this condition, the FRP can still resist stresses until FRP debonding occurs. Eq. 23 can thus be modified as follows (strengthening ratio>critical ratio):

$f_{d b}=\alpha 0.27 \tau_{\max } \sqrt{\frac{E_{F}}{t_{F}}} \alpha=\frac{\rho_{F}}{\rho_{c r-F}} \geq 1$

In comparison, most of the available bond strength models proposed in the literature, see e.g. [51,58,59], are obtained based on empirical modeling, fracture mechanics or experimental results [22] and have a general form of $f_{d b}=A \sqrt{E_{F} / t_{F}}$. As an example, JSCE 2001 [51] proposes the following relation:

$f_{d b}^{2}=8 \times E_{F} \times G_{F} / t_{F} \quad(N, m m)$

Assuming $\tau_{\max }=6.6 \sqrt{G_{f}}$ according to [28], this equation can be rewritten as follows: 
$f_{d b}=0.43 \tau_{\max } \sqrt{\frac{E_{F}}{t_{F}}}$

It can be observed that Eq. 24, proposal of this study, is similar to this relation with the difference of a multiplication factor $(\alpha)$. The advantage of the proposed formula is that it accounts for the effect of reinforcement ratio on the debonding strength.

\subsection{Effective bond length}

The FRP effective bond length is defined as the minimum length in which all the stresses are transferred from the FRP to the substrate. Accurate prediction of this length is critical in design and strengthening of RC elements for ensuring the full development of FRP capacity. Several relations have been proposed for effective bond length, but each one lead to different predictions and a unified relation does not exist yet [59].

A parameter study is performed here, following a similar procedure as presented in the last sections, for development of a micro-mechanics based formula for effective bond length. The results, presented in Fig. 17, led to the following relation:

$$
L_{e}=1.12 \sqrt{\frac{E_{F} t_{F}}{\tau_{\max }^{1.5}}}
$$

The so far existing relations are mostly in the form of $A \sqrt{E_{F} t_{F} / G_{f}}$. As an example, Dai et al. [59] proposed the following formula, based on analytical modeling of experimental results, for the effective bond length:

$$
L_{e}=\frac{1}{B} \sqrt{\frac{2 E_{F} t_{F}}{G_{f}}} \ln \left(\frac{1+\alpha}{1-\alpha}\right)
$$

Assuming $\alpha=0.96, B=10.4$ and $\tau_{\max }=0.5 B G_{\mathrm{f}}$ as suggested in $[59,60]$ gives the following relation which is slightly different than the one proposed in this study: 
$L_{e}=1.2 \sqrt{\frac{E_{F} t_{F}}{\tau_{\max }}}$

\section{Application to numerical modeling of FRP-strengthened components}

Considering the effect of FRP presence on the average response of concrete and reinforcing bars is critical for accurate numerical predictions using smeared crack modeling approach. This important issue, which has received less attention by the scientific community, is briefly investigated in this section. Based on a systematic parameter study performed using the developed computational framework, new formulas are proposed to calculate the bars average yield stress, FRP average debonding strength and concrete tension stiffening behavior. Application of the proposed average properties is then shown by numerically simulating the nonlinear response of two FRP-strengthened RC beams selected from the literature.

\subsection{Average properties for smeared crack modeling approach}

In RC elements, the reinforcing bars can yield at the crack plane while being elastic between two adjacent cracks. Depending on the reinforcement ratio, the average yield stress, $\overline{f_{y}}$, of reinforcing bars can thus be lower than the bare bars, see Fig. 18(a). Among the available models, the relation proposed by Salem [12] has been extensively used for obtaining the average yield stress of reinforcing bars in $\mathrm{RC}$ elements:

$\overline{f_{y}}=f_{y} \times\left(1-0.5 \frac{\rho_{c r-S}}{\rho_{S}}\right)$

Application of FRP, in FRP-strengthened RC elements, leads to reduction of crack spacing and increment of bars average yield stress, see Fig. 18(b). A parameter study on the effect of different parameters on average yield stress of reinforcing bars led to the following relation: 


$$
\overline{f_{y}}=f_{y}\left(1-0.5 \frac{f_{t}}{\rho_{F} \times f_{f}+\rho_{S} \times f_{y}}\right)
$$

here, $f_{\mathrm{f}}$ is obtained from Eq. 21. A similar parametric study led to the following relation for FRP average debonding strength in FRP-strengthened elements:

$\overline{f_{\max }}=f_{f} \times\left(\frac{\rho_{F}}{\rho_{c r-F}}-0.4\right) \leq F_{U-F}$

The tension stiffening behavior of cracked concrete can also be affected by the presence of FRP. The relation proposed by Maekawa et al. [53] has been extensively used for modeling the tension stiffening behavior of concrete in RC elements:

$\frac{f_{c 1}}{f_{c r}}=\left(\frac{\varepsilon_{c r}}{\varepsilon_{1}}\right)^{c}$

where $f_{\mathrm{c} 1}$ is the concrete tensile stress, $f_{\mathrm{cr}}$ is the concrete cracking strength, $\varepsilon_{\mathrm{cr}}$ is the concrete cracking strain (usually in the range of $0.01-0.03$ ), $\varepsilon_{1}$ is the concrete tensile strain and $c$ is a parameter that controls the tension stiffening behavior of concrete and is taken as 0.4 for deformed bars and 0.2 for welded wire mesh, see Fig. 19(a).

The performed analytical studies showed the tension stiffening behavior of concrete in FRPstrengthened RC elements has a good agreement with reinforced concrete elements, Eq. 33 (with $\mathrm{c}=0.2 \sim 0.4$ ), until FRP debonding occurs, see Fig. 19(b). After FRP debonding, the same tension stiffening curve can be used if the ratio of the existing reinforcing bars is higher than the critical reinforcement ratio. However, if the reinforcement ratio is less than the critical ratio, a drop in this curve is observed due to the decrement of transferrable stresses to the concrete. The following changes are therefore proposed for parameter $c$ in Eq. 33 for FRP-strengthened RC elements:

$c=c_{0}=0.2 \sim 0.4 \quad$ if $\left(\varepsilon<\varepsilon_{d b}\right)$ 
$c=c_{0}-\left(c_{0}-c_{g}\right) \frac{\varepsilon-\varepsilon_{d b}}{\varepsilon_{d b}} \leq c_{g} \quad$ if $\left(\varepsilon_{d b} \leq \varepsilon<2 \varepsilon_{d b}\right)$

$c=c_{g} \quad$ if $\left(\varepsilon \geq 2 \varepsilon_{d b}\right)$

where $\varepsilon_{\mathrm{db}}$ is the strain corresponding to the FRP debonding. $\mathrm{C}_{\mathrm{g}}$ can be used as 0.4 if the reinforcement is more than the critical ratio. In case if the reinforcement is less than the critical ratio, this value depends on several parameters such as element size and fracture energy but can be approximately used equal to 1 .

\subsection{Nonlinear analysis of selected beams}

The proposed average constitutive models for FRP-strengthened concrete elements are used in this section for simulating the nonlinear response of two FRP-strengthened RC beams selected from the literature [61]. The beams were constructed with a length of $4500 \mathrm{~mm}$, width of $180 \mathrm{~mm}$, height of $500 \mathrm{~mm}$ and effective height of $425 \mathrm{~mm}$. Twelve longitudinal bars with $d_{\mathrm{b}}=16 \mathrm{~mm}$ were placed at the bottom (in the tensile region) and two with $d_{\mathrm{b}}=16 \mathrm{~mm}$ at the top (in the compressive region) of the beams with no stirrups. The beams were strengthened with different FRP thickness and directions. Four point bending tests were performed on the beams to investigate the effect of FRP strengthening on their mechanical performance. The beams RC1 and $\mathrm{C} 5$, strengthened with diagonal FRP sheets, are selected here for numerical simulation. The material properties, reported in [61], are presented in Table 4.

The beams are simulated in WCOMD program according to the experimental conditions. The average material properties, obtained according to the proposed relations in the last section, are used as the input of the numerical model. Eqs. 33-34 are used for modeling the tension stiffening of the concrete. In these equations, it is assumed that $c=0.25$ for the plain concrete elements or elements with reinforcement ratio less than the critical ratio, $\mathrm{c}=0.2$ for $\mathrm{RC}$ elements reinforced 
with FRP, and $\mathrm{c}=0.4$ for $\mathrm{RC}$ elements. Nonlinear static analysis is performed on the beams according to the experimental details to simulate the force-displacement curves and load bearing capacity.

The numerical force-displacement curves, presented in Fig. 20, shows a good agreement with experimental results. The stiffness and load bearing capacity of the beams is fairly near to the experimental results showing the suitability of the proposed modifications in the material properties. The numerical results show $13.83 \%$ and $6.5 \%$ underestimation of the capacity of the C5 and RC1 beams, respectively, compared to the experimental results. Although the numerical predictions are in an acceptable range, a deeper analysis of the accuracy of the proposed formulations and modeling strategy in predicting the nonlinear response of FRP-strengthened RC beams will be further investigated in future studies.

\section{Conclusions}

A computational framework was presented for simulating the tensile response and tension stiffening behavior of FRP-strengthened RC elements. In this model, all the local stress transfer mechanisms at the crack plane including the concrete bridging stresses, steel tensile behavior, FRP tensile behavior and the interactions between them (i.e. the bond behavior at FRP-concrete and bars-concrete interfaces) are simulated. Based on the developed model, the cracking response and tension stiffening behavior of FRP-strengthened RC elements can be followed.

The model, after validation with experimental results, was used for development of micromechanics-based design relations for calculating the crack spacing, FRP critical ratio, FRP debonding strength and effective bond length in FRP-strengthened RC elements. Among the advantages of the proposed relations are that (i) the relations are obtained based on micromechanical modeling, thus have a physical background for each mechanism in contrary to 
the empirical-based or experimental-based relations that are usually obtained by regression analysis and fitting, and (ii) the relations are applicable for investigating the mechanics of undamaged and deteriorated elements. The latter can be achieved by simply implementing the deteriorated material/bond properties in the simulation to investigate the effect of local material degradation on the structural response of strengthened RC components.

The results from analytical simulations showed that the FRP presence affect the average response of reinforcing bars and of concrete tension stiffening behavior. Based on a systematic parameter study, suitable constitutive models were proposed for each of these mechanisms. The application of the proposed models in smeared crack modeling was also shown by simulating the nonlinear response and load bearing capacity of two FRP-strengthened RC beams selected from literature. Detailed analysis of the accuracy of the proposed formulations will have to be followed with further comparisons with experimental results in future works.

\section{Acknowledgements}

The first author acknowledges the financial support of the European Union's Marie Curie Individual Fellowship program under REA grant agreement No. 701531. The authors greatly acknowledge Professor Koichi Maekawa at Civil Engineering Department of The University of Tokyo for supporting this study by providing the WCOMD software.

\section{References}

[1] Limam O, Foret G, Ehrlacher A. RC beams strengthened with composite material: a limit analysis approach and experimental study. Compos Struct 2003;59:467-72.

[2] De Domenico D, Fuschi P, Pardo S, Pisano AA. Strengthening of steel-reinforced concrete structural elements by externally bonded FRP sheets and evaluation of their load carrying capacity. Compos Struct 2014;118:377-84.

[3] Dai JG, Ueda T, Sato Y, Nagai K. Modeling of Tension Stiffening Behavior in FRPStrengthened RC Members Based on Rigid Body Spring Networks. Comput Civ Infrastruct 
Eng 2012;27:406-18. doi:10.1111/j.1467-8667.2011.00741.x.

[4] Yang G, Zomorodian M, Belarbi A, Acun B. Tension Stiffening of Reinforced Concrete Shear Elements Strengthened with Externally Bonded FRP Sheets Tension Stiffening of Reinforced Concrete Shear Elements Strengthened with Externally Bonded FRP Sheets Experimental Program. 37th IABSE Symp., vol. 102, Madrid: 2014, p. 145-52.

[5] Sato Y, Vecchio FJ. Tension Stiffening and Crack Formation in Reinforced Concrete Members with Fiber-Reinforced Polymer Sheets. J Struct Eng ASCE 2003;129:717-24.

[6] Ceroni F, Pecce M, Mathys S. Tension stiffening of reinforced concrete ties strengthened with externally bonded fiber-reinforced polymer sheets. J Compos Constr ASCE 2004;8:22-32.

[7] Pecce M, Ceroni F. Modeling of Reinforced Concrete Ties Strengthened with Fiber Reinforced Plastic Sheets. J Compos Constr 2004;8:510-8.

[8] Ueda T, Yamaguchi R, Shoji K, Sato Y. Study on Behavior in Tension of Reinforced Concrete Members Strengthened by Carbon Fiber Sheet. J Compos Constr 2002;6:168-74.

[9] Baena M, Torres L, Turon A, Miàs C. Analysis of cracking behaviour and tension stiffening in FRP reinforced concrete tensile elements. Compos Part B Eng 2013;45:1360-7.

[10] Ferretti D, Savoia M. Non-linear model for R/C tensile members strengthened by FRPplates. Eng Fract Mech 2003;70:1069-83.

[11] Yang G, Zomorodian M, Belarbi A. Material Laws of FRP-Strengthened RC Element in Biaxial Tension-Compression. J Compos Constr 2017;21:4017030.

[12] Salem HMM. Enhanced tension stiffening model and application to nonlinear dynamic analysis of reinforced concrete. The University of Tokyo, 1998.

[13] Russo G, Romano F. Cracking response of RC members subjected to uniaxial tension. J Struct Eng ASCE 1992;118:1172-90.

[14] Torres L, López-Almansa F, Bozzi L. Tension-stiffening model for cracked flexural concrete members. J Struct Eng ASCE 2004;130:1242-51.

[15] Lee G, Kim W. Cracking and tension stiffening behavior of high strength concrete tension members subjected to axial load. 2009;12(2):127-37. Adv Struct Eng 2009;12:127-37.

[16] Ferretti D, Savoia M. Cracking evolution in RC tensile members strengthened by FRPplates. Eng Fract Mech 2003;70:1069-83.

[17] Gupta AK, Maestrini SR. Post-Cracking Behavior of Membrane Reinforced Concrete Elements Including Tension-Stiffening. J Struct Eng ASCE 1989;115:957-76.

[18] Pérez Caldentey A, Corres Peiretti H, Giraldo Soto A, Peset Iribarren J. Cracking of RC members revisited: Influence of cover, $\varphi / \rho \mathrm{s}$, ef and stirrup spacing - An experimental and theoretical study. Struct Concr 2013;14:69-78.

[19] Gribniak V, Pérez Caldentey A, Kaklauskas G, Rimkus A, Sokolov A. Effect of arrangement of tensile reinforcement on flexural stiffness and cracking. Eng Struct 2016;124:418-28. doi:10.1016/j.engstruct.2016.06.026.

[20] Kaklauskas G, Ph D, Sc D. Crack Model for RC Members Based on Compatibility of StressTransfer and Mean-Strain Approaches 2017;143:1-12.

[21] Kaklauskas G, Ramanauskas R, Jakubovskis R. Mean crack spacing modelling for RC tension elements. Eng Struct 2017;150:843-51. doi:10.1016/j.engstruct.2017.07.090.

[22] Chen JF, Teng JG. Anchorage strength models for FRP-to-concrete bonded joints. J Struct Eng ASCE 2001;127:784-91.

[23] Soltani M, An X, Maekawa K. Computational model for post cracking analysis of RC membrane elements based on local stress - strain characteristics. Eng Struct 2003;25:993- 
1007.

[24] Farah K, Sato Y. Uniaxial Tension Behavior of Reinforced Concrete Members Strengthened with Carbon Fiber Sheets. J Compos Constr 2011;15:215-28.

[25] Ghiassi B, Soltani M, Pourkeramat P. Local stress field approach for post cracking analysis of FRP strengthened RC elements. Compos Part B 2013;53:234-48.

[26] Ushida Y, Rokugo K, Koyanagi W. Determination of tension softening diagrams of concrete by means of bending tests. Proc JSCE 1991;14:203-12.

[27] Shima H, Chou L, Okamura H. Micro and macro models for bond in reinforced concrete. J Fac Univ Tokyo 1987;39:133-94.

[28] Nakaba K, Kanakubo T, Furuta T, Yoshizawa H. Bond Behavior between Fiber-Reinforced Polymer Laminates and Concrete. ACI Struct J 2001;98:1-9.

[29] Bazant ZP, Planas J. Fracture and size effect in concrete and other quasi brittle materials. 1998.

[30] Ramachandra Murthy A, Karihaloo BL, Iyer NR, Raghu Prasad BK. Bilinear tension softening diagrams of concrete mixes corresponding to their size-independent specific fracture energy. Constr Build Mater 2013;47:1160-6.

[31] Guinea GV, Planas J, Elices M. A general bi-linear fit for the softening curve of concrete. Mater Struct 1994;27:99-105.

[32] Roesler J, Paulino GH, Park K, Gaedicke C. Concrete fracture prediction using bilinear softening. Cem Conc Compos 2007;29:300-12.

[33] Chen HH, Su RKL. Tension softening curves of plain concrete. Constr Build Mater 2013;44:440-51.

[34] Japanese Society of Civil Engineering (JSCE). STANDARD SPECIFICATIONS FOR CONCRETE STRUCTURES 2007 “Design.” 2007.

[35] CEB-FIP. Model Code 1990. 1990.

[36] Bažant ZP, Becq-Giraudon E. Statistical prediction of fracture parameters of concrete and implications for choice of testing standard. Cem Concr Res 2002;32:529-56.

[37] CEB-FIP. Bulletin 55 - Model Code 2010 - First Complete Draft, Volume 1. International federation for structural concrete (fib). Lausanne, Switzerland: 2010.

[38] Wu Y-F, Zhao X-M. Unified bond stress-slip model for reinforced concrete. J Struct Eng 2012;139:1951-62.

[39] Guizani L, Chaallal O, Mousavi SS. Local bond stress-slip model for reinforced concrete joints and anchorages with moderate confinement 2015;44:201-11. doi:10.1139/cjce-20150333.

[40] Shima H, Chou LL, Okamura H. Micro and macro models for bond in reinforced concrete. J Fac Eng Uinversity Tokyo 1987;39(2):133-194.

[41] Kankam CK. Relationship of Bond Stress, Steel Stress, and Slip in Reinforced Concrete. ASCE J Struct Eng 1997;123:79-85.

[42] Wu HQ, Gilbert RI. Modeling short-term tension stiffening in reinforced concrete prisms using a continuum-based finite element model. Eng Struct 2009;31:2380-91.

[43] Soltani M, Maekawa K. Path-dependent mechanical model for deformed reinforcing bars at RC interface under coupled cyclic shear and pullout tension 2008;30:1079-91.

[44] Goto Y. Cracks formed in concrete around deformed tension bars. ACI J 1971;68:244-51.

[45] Shin H. Finite element analysis of reinforced concrete members subjected to reversed cyclic in-plane loadings. University of Tokyo, 1988.

[46] Qureshi J, Maekawa K. Computational model for steel embedded in concrete under 
combined axial pullout and transverse shear displacement. Proc JCI 1993;15:1249-54.

[47] Obaidat YT, Heyden S, Dahlblom O. The effect of CFRP and CFRP/concrete interface models when modelling retrofitted RC beams with FEM. Compos Struct 2010;92:1391-8.

[48] Yuan H, Lu X, Hui D, Feo L. Studies on FRP-concrete interface with hardening and softening bond-slip law. Compos Struct 2012;94:3781-92.

[49] Martinelli E, Caggiano A. A unified theoretical model for the monotonic and cyclic response of FRP strips glued to concrete. Polymers (Basel) 2014;6:370-81.

[50] CNR-DT 204/2006 Guide for the Design and Construction of Fiber-Reinforced Concrete Structures 2007:57.

[51] Japanese Society of Civil Engineering (JSCE). Recommendations for upgrading of concrete structures with use of continuouse fiber sheets. Tokyo, Japan: 2001.

[52] Ghiassi B, Soltani M. Local Stress Field Approach for Shear Failure Assessment of Reinforced Concrete Members. J Adv Concr Technol 2010;8:223-38. doi:10.3151/jact.8.223.

[53] Maekawa K, Pimanmas A, Okamura H. Nonlinear Mechanics of Reinforced Concrete. Spon Press; 2003.

[54] Beeby A. A study of cracking in reinforced concrete members subjected to pure tension. Technical Report 42.468. London: 1972.

[55] Rizkalla SH, Hwang LS, El-Shahawi M. Transverse reinforcement effect on cracking behavior of R.C. members. Canad J Civ Eng 1983;10:556-81.

[56] EC2. Eurocode 2. Design of concrete structures-Part I: General rules and rules for buildings. Paris: 2004.

[57] CSA. Canadian Standard Associations. S474 concrete structures. Mississauga (Ontario, Canada). 2004.

[58] CNR-DT 200. Guide for the design and construction of externally bonded FRP systems for strengthening existing structures. Rome: National Research Council; 2004.

[59] Dai J, Ueda T, Sato Y. Unified Analytical Approaches for Determining Shear Bond Characteristics of FRP-Concrete Interfaces through Pullout Tests. J Adv Concr Technol 2006;4:133-45.

[60] Ueda T, Dai JG. Interface bonds between FRP sheets and concrete substrates: properties, numerical modeling and roles in member behavior. Prof Struct Engng Mater 2005;7:27-43.

[61] Taljesten B. Stengthening concrete beams for shear with CFRP sheets. Constr Build Mater $2003 ; 17: 15-26$.

[62] Broms B. Crack width and crack spacing in reinforced concrete members. ACI J 1965;62:1237-56.

[63] Khalifa A, Nanni A. Rehabilitation of rectangular supported RC beams with deficiencies using CFRP composites. Constr Build Mater 2002;16:135-46. 


\section{List of Tables}

Table 1. Analytical formulas for calculation of fracture energy of plain concrete.

Table 2. Analytical formulas for calculation of crack spacing in reinforced concrete.

Table 3. Properties and retrofitting details of the selected specimens for validation, taken from [6].

Table 4. Material properties of the selected beams, taken from [62].

\section{List of Figures}

Fig. 1. Stress state in cracked FRP reinforced concrete tensile members.

Fig. 2. Bond stress transfer at the bar-to-concrete and FRP-to-concrete interfaces.

Fig. 3. Fracture energy of plain concrete in terms of compressive strength.

Fig. 4. Bond stress and strain distribution along the reinforcing bars.

Fig. 5. Bond deterioration at crack plane.

Fig. 6. State of stresses along each segment of reinforcing bars.

Fig. 7. Flowchart for computing the stress-strain profile along the reinforcing bars.

Fig. 8. Flowchart for computing the stress-strain profile along the FRP sheets.

Fig. 9. Flowchart of computation.

Fig. 10. (a) Effect of $\tau_{\max }$ on the tensile response of TP1-C1 specimen; (b) FRP-concrete bond stress variation with load increment in TP1-C1 with $\tau b F y=4.5 \mathrm{MPa}$.

Fig. 11. Effect of concrete fracture energy on tension stiffening response of TP1-C1.

Fig. 12. Comparison of experimental and numerical results: (a) TP1-C1; (b) TP1-G4; (c) TP2-C2; (d) TP2-G4.

Fig. 13. (a) Concrete tension stiffening; (b) FRP/steel average response.

Fig. 14. Parametric study on crack spacing in FRP strengthened plain concrete elements.

Fig. 15. Parametric study on FRP critical ratio.

Fig. 16. Procedure followed for obtaining the FRP critical ratio.

Fig. 17. Parametric study on FRP effective bond length.

Fig. 18. Average response of reinforcing bars in: (a) RC elements; (b) FRP-strengthened RC elements.

Fig. 19. Tension stiffening model for: (a) RC elements [48]; (b) FRP-strengthened RC elements.

Fig. 20. Experimental and numerical response of FRP-strengthened RC beams: (a) RC1; (b) C-5. 
Table 1. Analytical formulas for calculation of fracture energy of plain concrete.

\begin{tabular}{|l|c|}
\hline Reference & Formula \\
\hline CEB-FIP-90 [35] & $G_{f}=\left(0.0469 d_{\text {max }}^{2}-0.5 d_{\text {max }}+26\right) \times\left(\frac{f^{\prime}}{10}\right)^{0.7}$ \\
\hline CEB-FIP 2010 [37] & $G_{f}=73 \times\left(\frac{f_{c}^{\prime}}{10}\right)^{0.18}$ \\
\hline JSCE [34] & $G_{f}=10 \times d_{\max }^{0.33} \times{f^{\prime}}_{c}^{0.33}$ \\
\hline Bazant and Becq-Giraudon [36]* & $G_{f}=2.5 \alpha_{\circ}\left(\frac{f^{\prime}{ }_{c}}{0.051}\right)^{0.46}\left(1+\frac{d_{\text {max }}}{11.27}\right)^{0.22}\left(\frac{w_{c}}{{ }^{-0.3}}{ }^{-0.3}\right.$ \\
\hline
\end{tabular}

$*_{\alpha}$ is 1 for rounded aggregate and 1.44 for crushed aggregates; w/c is the water to cement ratio

Table 2. Analytical formulas for calculation of crack spacing in reinforced concrete.

\begin{tabular}{|l|l|c|}
\hline Year & Reference & Formula \\
\hline 1965 & Broms (1965) [62] & $S_{s}=2 C$ \\
\hline 1972 & Beeby (1972) [54] & $S_{s}=1.33 C+0.08 d / \rho_{s}$ \\
\hline 1983 & Rizkalla et al. (1983) [55] & $S_{s}=5(d-7.2)+1.33 C+0.08 d / \rho_{s}$ \\
\hline 1990 & CEB-FIP 1990 [35]* & $S_{s}=\frac{2}{3} d \frac{A_{c}}{3.6 A_{s}}$ \\
\hline 1998 & Salem (1998) [12] & $S_{s}=1.76 \rho_{s}{ }^{-0.5} f_{y}{ }^{0.1} f^{\prime}{ }^{-0.4} d\left(1+f_{t}\right)$ \\
\hline 2004 & EC2 (2004) [56] ${ }^{* *}$ & $S_{s}=2 C+k_{1} k_{2} d \frac{A_{c}}{4 A_{s}}$ \\
\hline 2017 & Kaklauskas et al. (2017) [21]*** & $S_{s}=0.44\left(d-y_{0}\right)+\frac{1000}{3} \varepsilon_{s} d+E_{s} d \frac{\varepsilon_{s}-\varepsilon_{s 0}}{f^{\prime}{ }_{c}}$ \\
\hline
\end{tabular}

* $A_{\mathrm{s}}$ is the reinforcement area and $A_{\mathrm{c}}$ concrete effective area.

$* * k_{1}=0.8$ for deformed bar and 1.6 for plain bar; $k_{2}=0.5$ for bending and 1.0 for pure tension.

$* * * \varepsilon_{s}$ is the reinforcement strain at crack and $\varepsilon_{s 0}$ is the minimum reinforcement strain between two cracks 
Table 3. Properties and retrofitting details of the selected specimens for validation, taken from [6].

\begin{tabular}{|c|c|c|c|c|c|c|c|c|c|c|c|c|}
\hline \multirow{2}{*}{ Specimen } & \multicolumn{2}{|c|}{ Concrete } & \multicolumn{5}{|c|}{ Reinforcing bars } & \multicolumn{5}{|c|}{ FRP } \\
\hline & $\begin{array}{c}f_{\mathrm{c}} \\
(\mathrm{MPa})\end{array}$ & $\begin{array}{c}f_{\mathrm{t}} \\
(\mathrm{MPa})\end{array}$ & $\begin{array}{c}d_{\mathrm{b}} \\
(\mathrm{mm})\end{array}$ & $\begin{array}{c}f_{\mathrm{y}} \\
(\mathrm{MPa})\end{array}$ & $\begin{array}{c}f_{\mathrm{su}} \\
(\mathrm{MPa})\end{array}$ & $\begin{array}{c}E_{\mathrm{s}} \\
(\mathrm{GPa})\end{array}$ & $\begin{array}{c}\rho_{\mathrm{s}} \\
(\%)\end{array}$ & $\begin{array}{c}\text { FRP } \\
\text { Type* }\end{array}$ & $\begin{array}{c}\text { FRP } \\
\text { Layers }\end{array}$ & $\begin{array}{c}f_{f u} \\
(\mathrm{MPa})\end{array}$ & $\begin{array}{c}\rho_{\text {FRP }} \\
(\%)\end{array}$ & $\begin{array}{r}E_{\mathrm{FRP}} \\
(\mathrm{GPa})\end{array}$ \\
\hline TP1-C1 & 31.6 & 2.6 & 10 & 588 & 670 & 200 & 0.785 & CFRP & 1 & 2830 & 0.222 & 270 \\
\hline TP1-G4 & 31.6 & 2.6 & 10 & 588 & 670 & 200 & 0.785 & GFRP & 4 & 1016 & 0.800 & 65 \\
\hline TP2-C2 & 34.7 & 2.7 & 14 & 560 & 633 & 200 & 1.539 & CFRP & 2 & 2830 & 0.444 & 270 \\
\hline TP2-G4 & 34.7 & 2.7 & 14 & 560 & 633 & 200 & 1.539 & GFRP & 4 & 1016 & 0.800 & 65 \\
\hline
\end{tabular}

$* t_{\mathrm{F}}(\mathrm{GFRP})=0.1$ and $t_{\mathrm{F}}(\mathrm{GFRP})=0.111[6]$.

Table 4. Material properties of the selected beams, taken from [63].

\begin{tabular}{|c|c|c|c|c|c|c|c|c|}
\hline \multirow{2}{*}{$\begin{array}{c}\text { Specimen } \\
\text { type }\end{array}$} & \multicolumn{2}{|c|}{ Concrete } & \multicolumn{3}{c|}{ Reinforcing bars } & \multicolumn{3}{c|}{ CFRP } \\
\cline { 2 - 9 } & & & & & & & & \\
\hline RC1 & 67.4 & 45.1 & 16 & 500 & 210 & 0.11 & 4500 & 234 \\
\hline C5 & 71.4 & 46.5 & 16 & 500 & 210 & 0.17 & 4500 & 234 \\
\hline
\end{tabular}




\section{Local stresses}
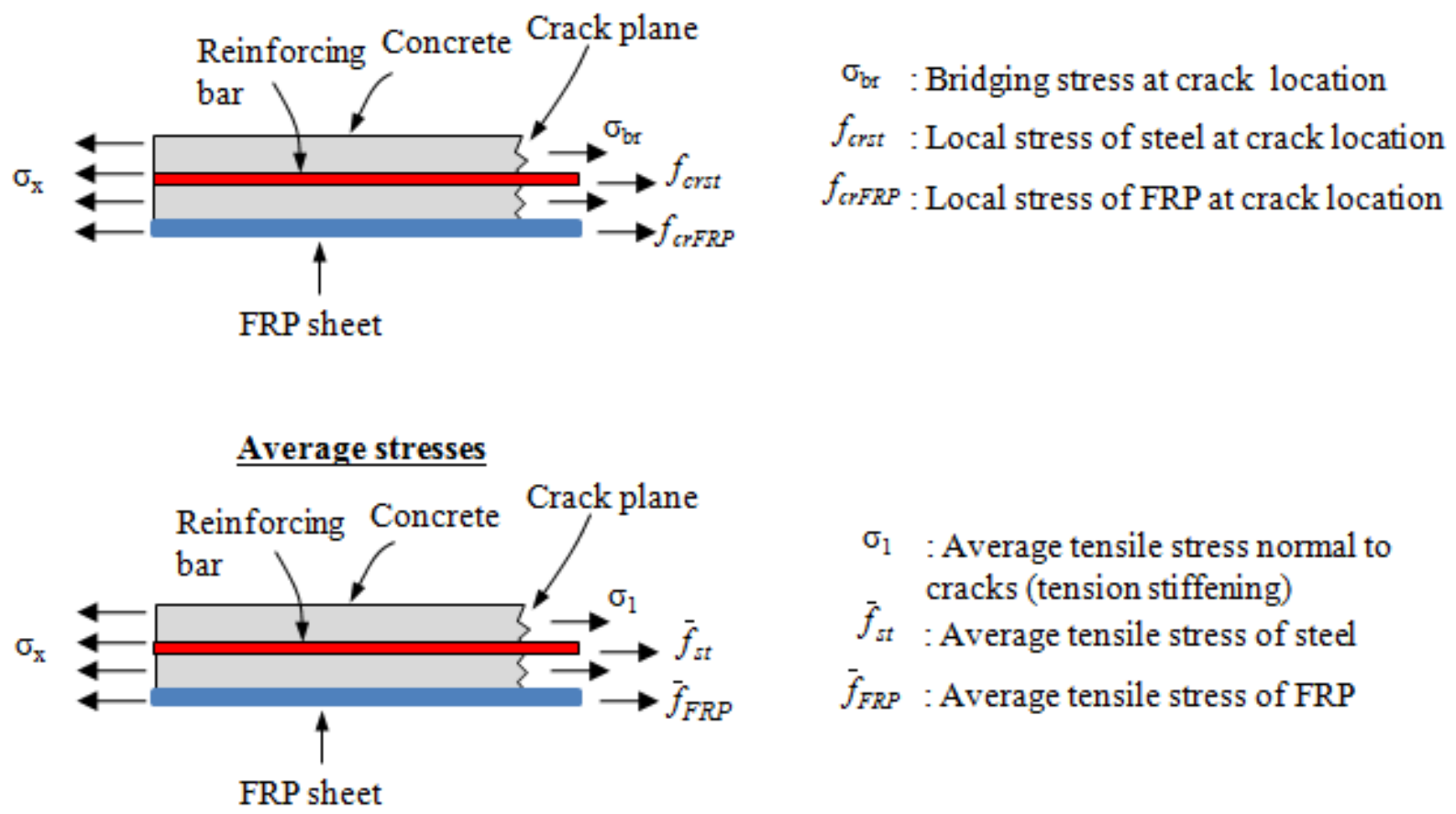

Fig. 1. Stress state in cracked FRP reinforced concrete tensile members. 


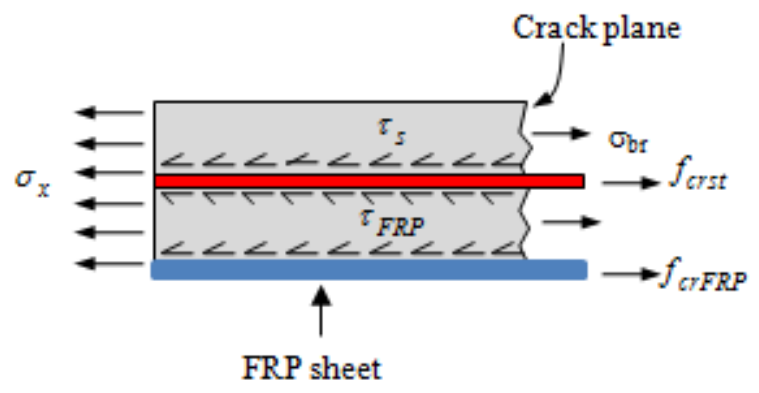

Fig. 2. Bond stress transfer at the bar-to-concrete and FRP-to-concrete interfaces. 




Fig. 3. Fracture energy of plain concrete in terms of compressive strength. 


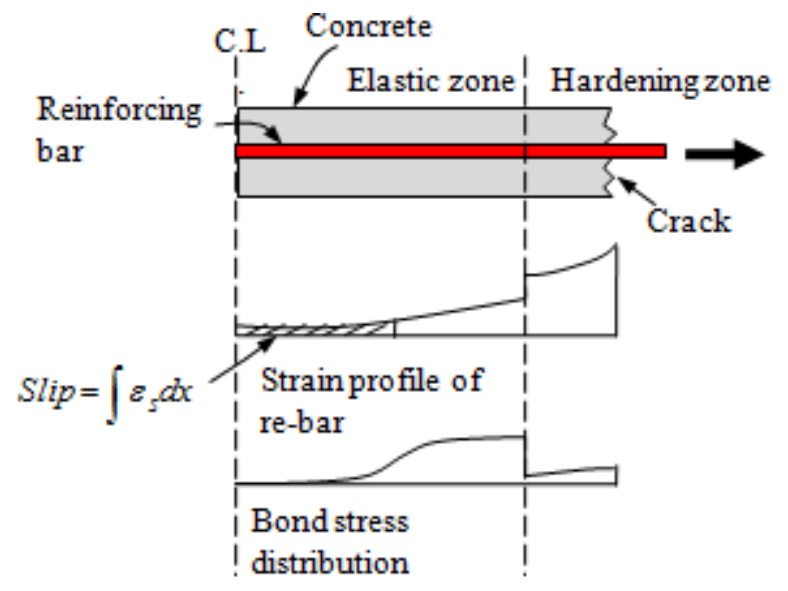

Fig. 4. Bond stress and strain distribution along the reinforcing bars. 


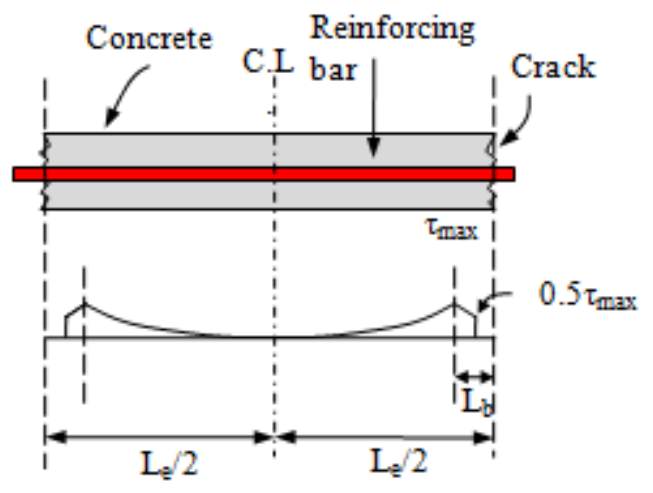

Fig. 5. Bond deterioration at crack plane. 


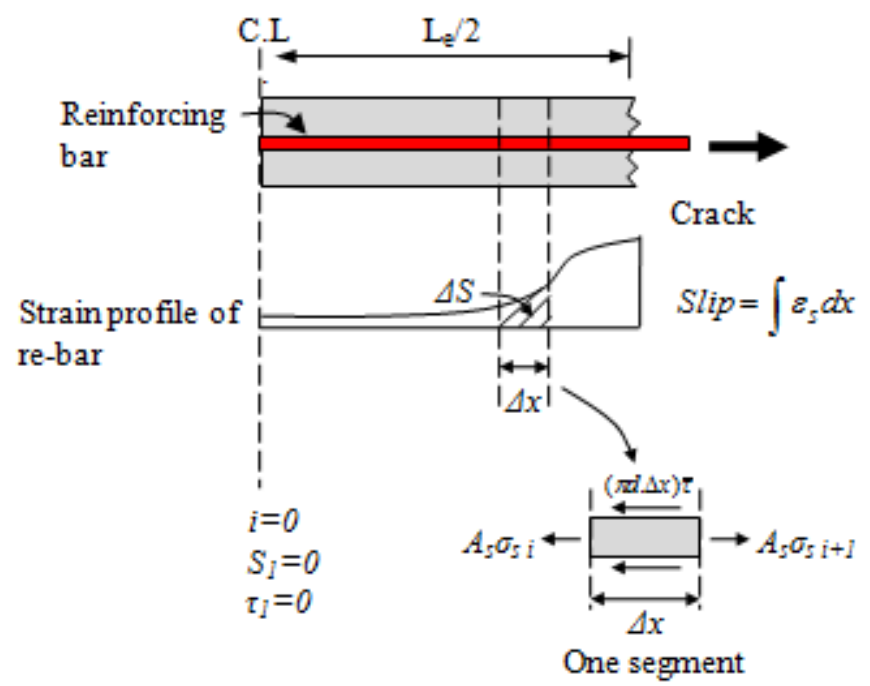

Fig. 6. State of stresses along each segment of reinforcing bars. 


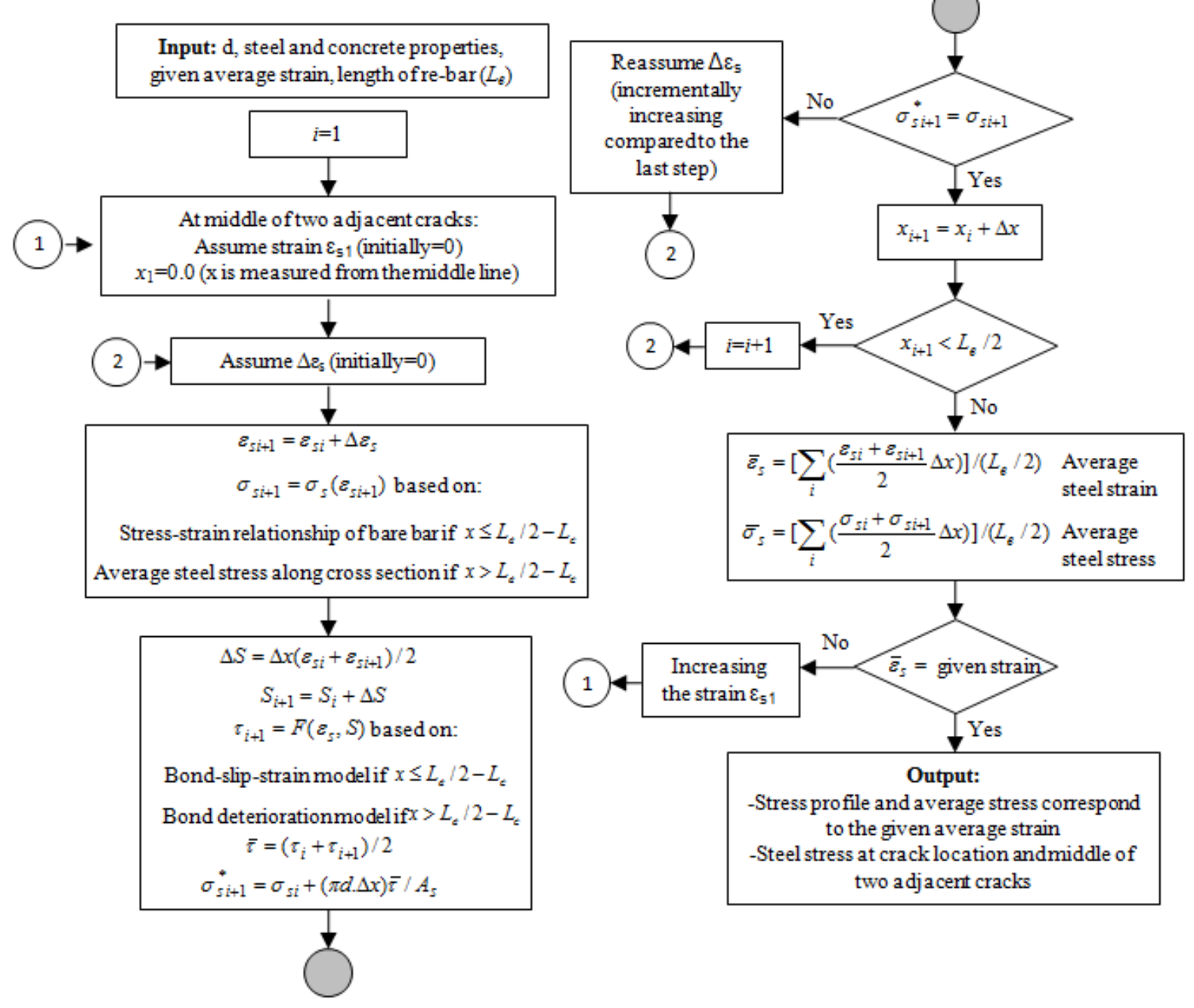

Fig. 7. Flowchart for computing the stress-strain profile along the reinforcing bars. 


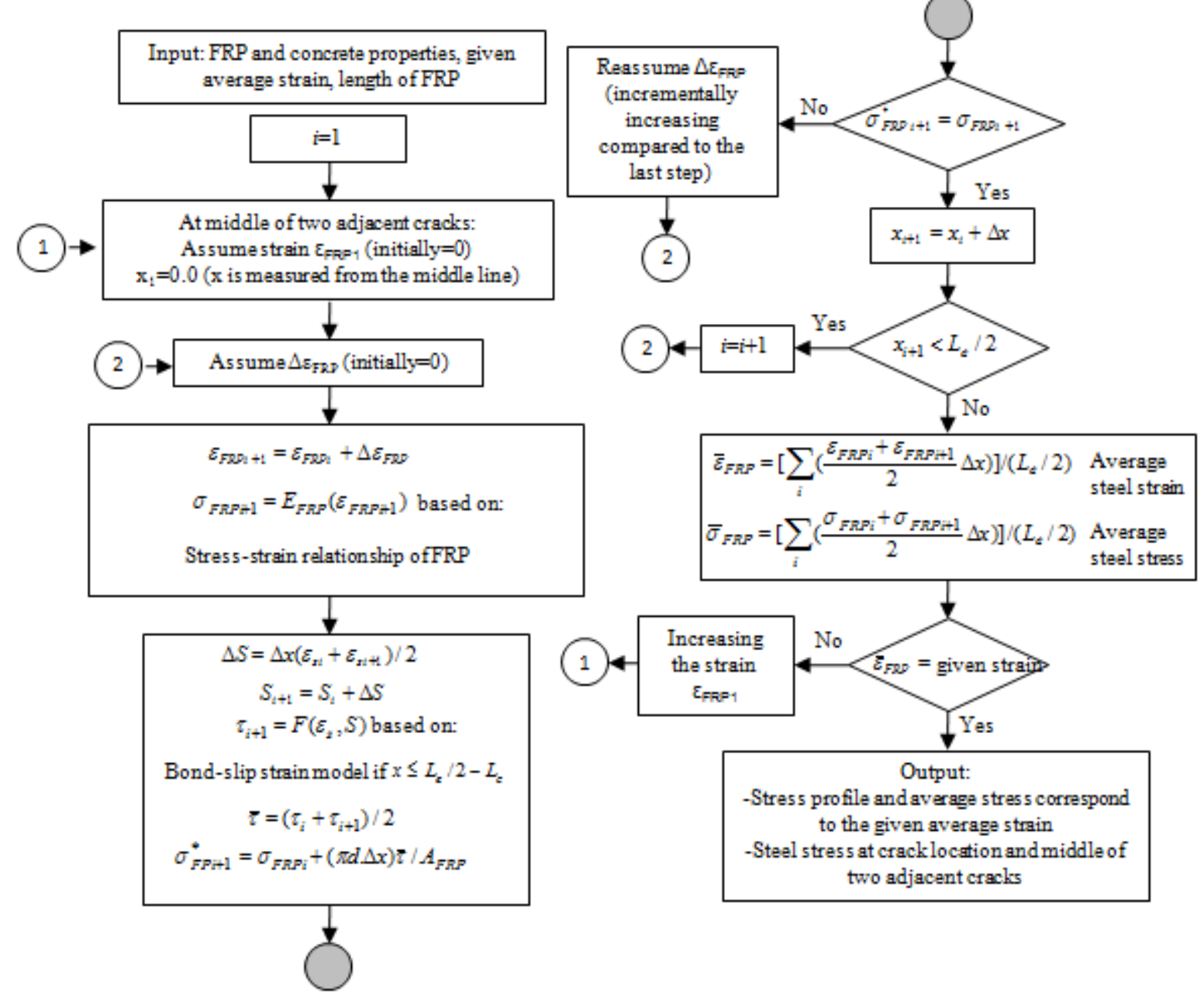

Fig. 8. Flowchart for computing the stress-strain profile along the FRP sheets. 


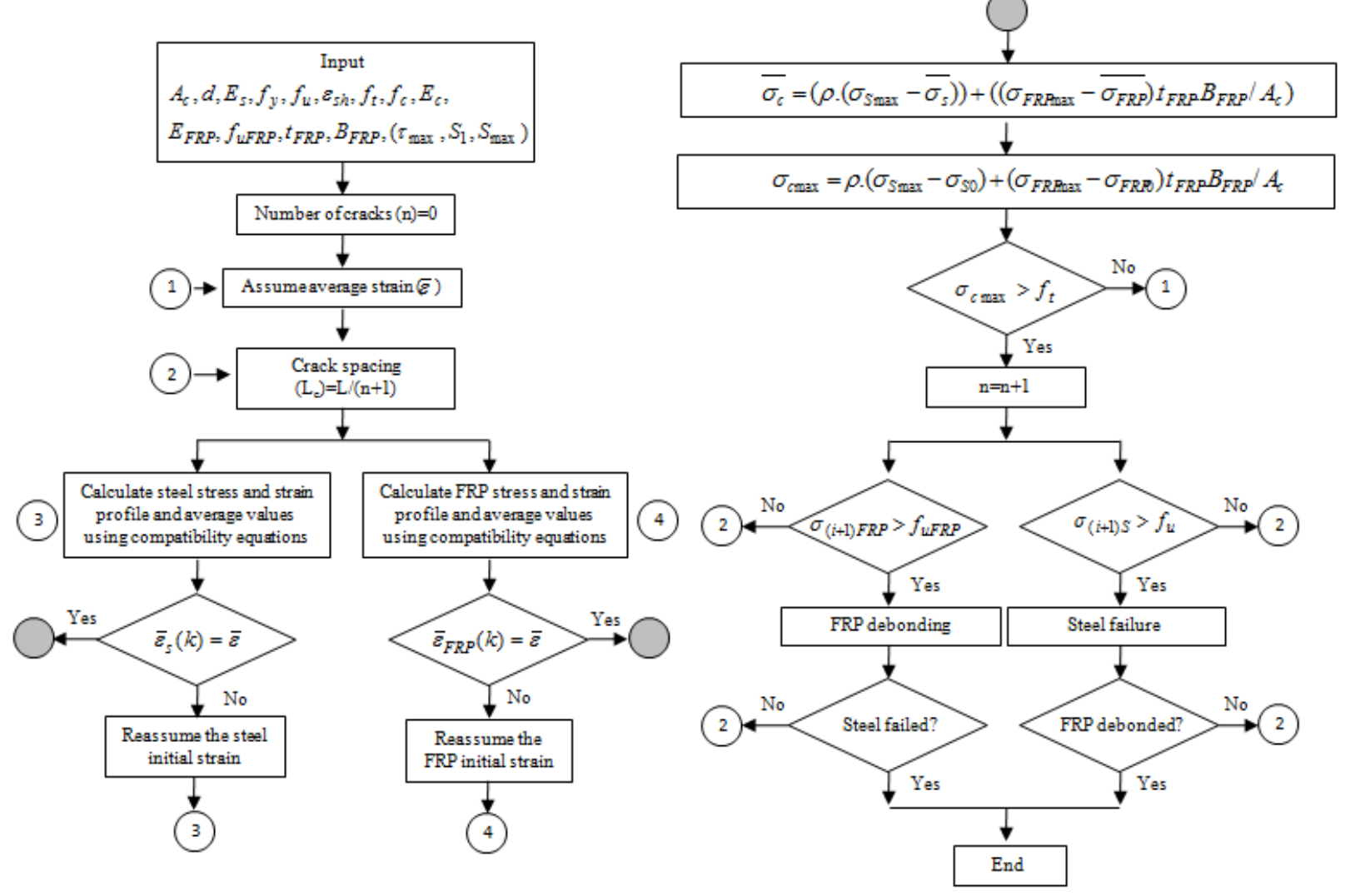

Fig. 9. Flowchart of computation of the tensile response of FRP-strengthened element. 




(a)

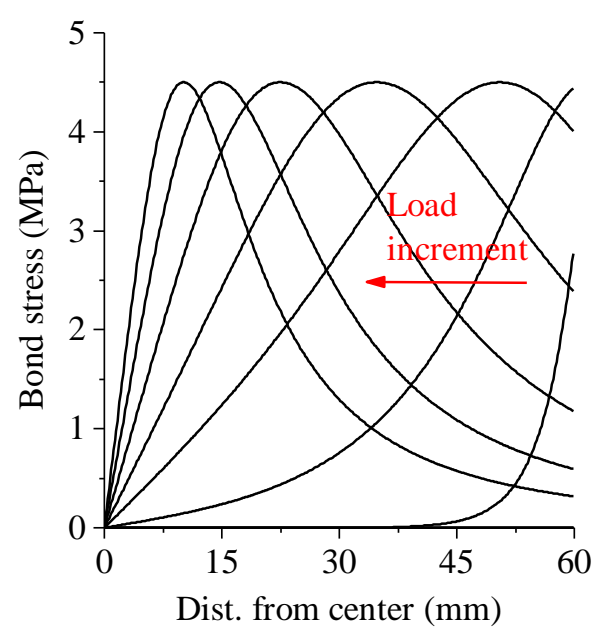

(b)

Fig. 10. (a) Effect of $\tau_{\max }$ on the tensile response of TP1-C1 specimen; (b) FRP-concrete bond stress variation with load increment in TP1-C1 with $\tau_{b F y}=4.5 \mathrm{MPa}$. 


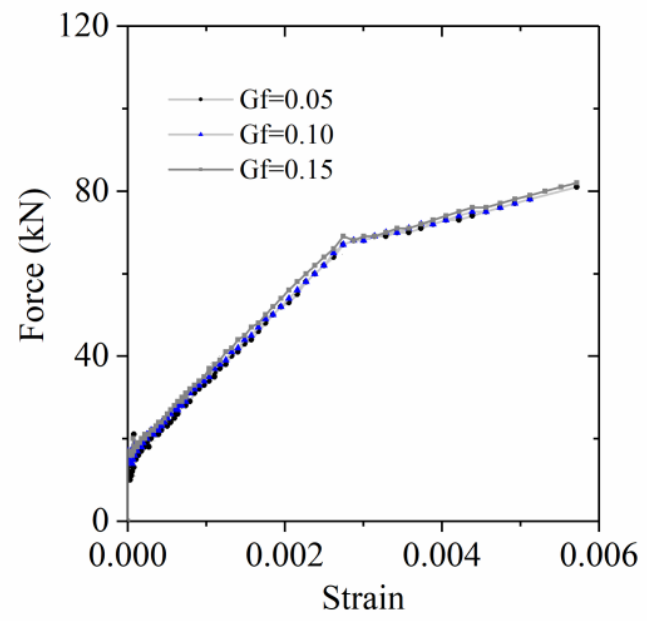

Fig. 11. Effect of concrete fracture energy on tension stiffening response of TP1-C1 specimen. 


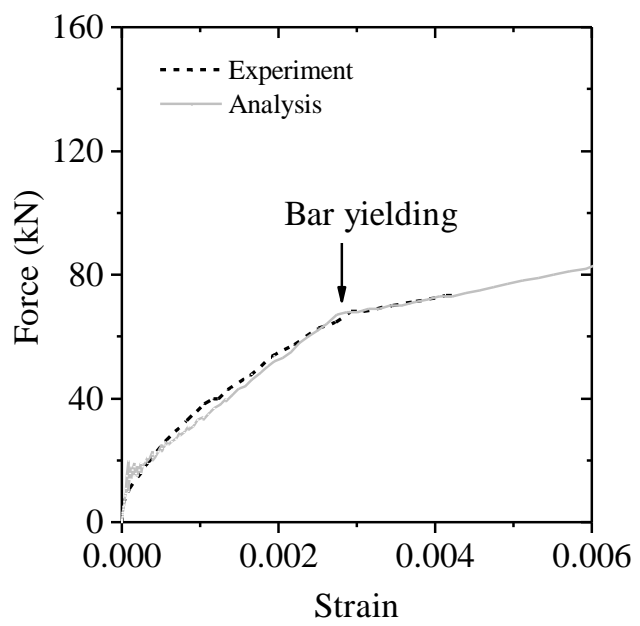

(a)

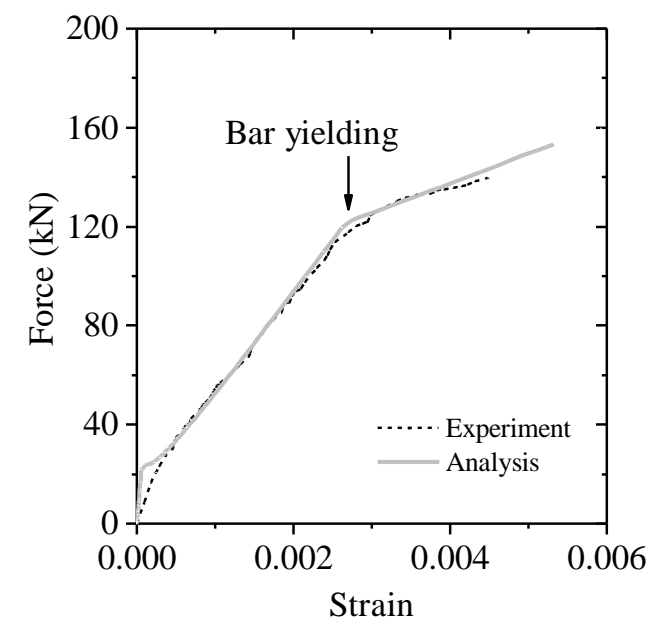

(c)

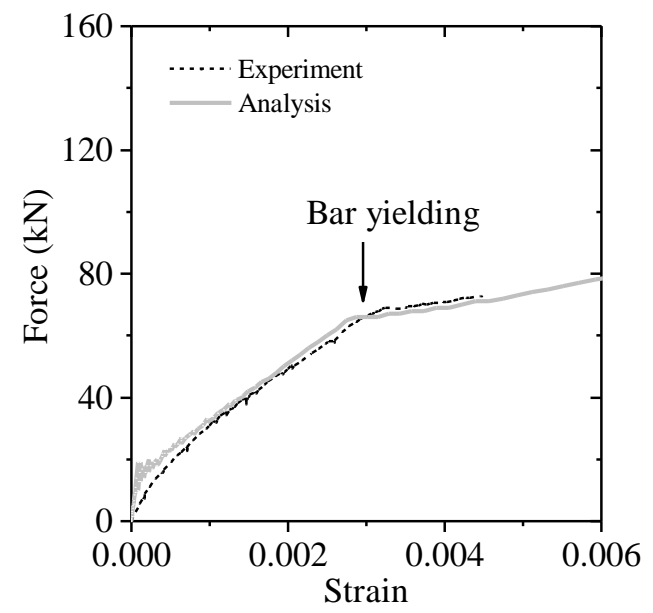

(b)

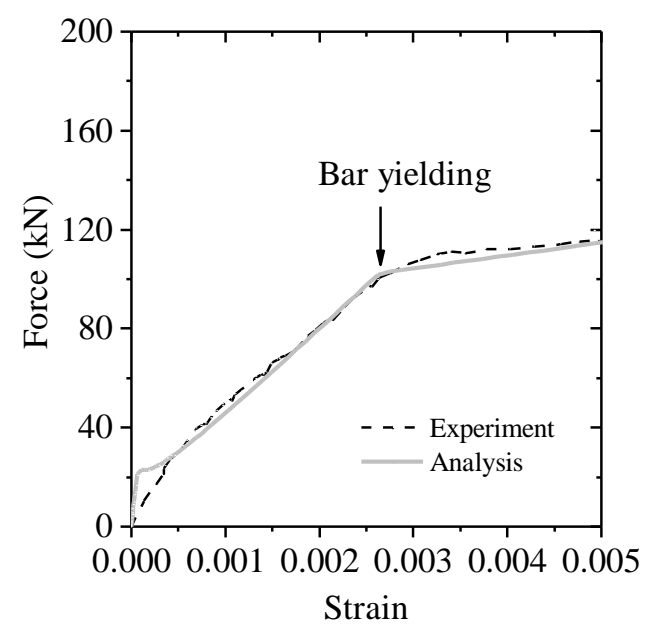

(d)

Fig. 12. Comparison of experimental and numerical results: (a) TP1-C1; (b) TP1-G4; (c) TP2C2; (d) TP2-G4. 


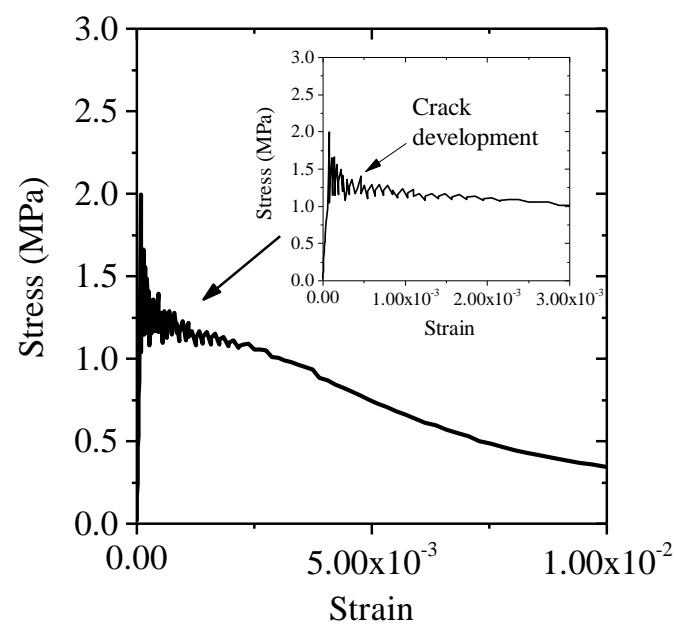

(a)

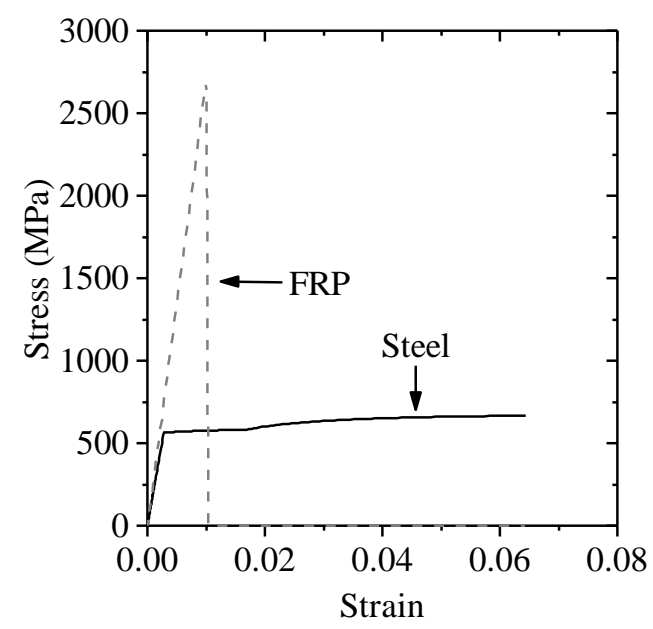

(b)

Fig. 13. (a) Concrete tension stiffening; (b) FRP/steel average response. 




Fig. 14. Parametric study on crack spacing in FRP-strengthened plain concrete elements. 




Fig. 15. Parametric study on FRP critical ratio in FRP-strengthened plain concrete elements. 


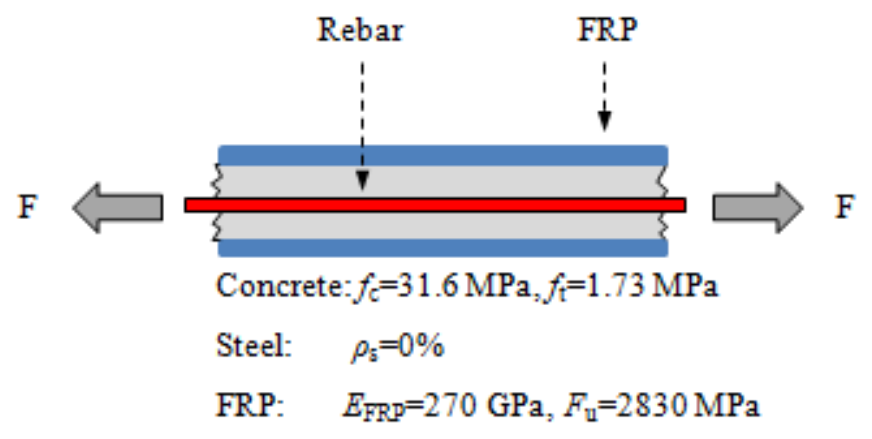

Parametric Study:

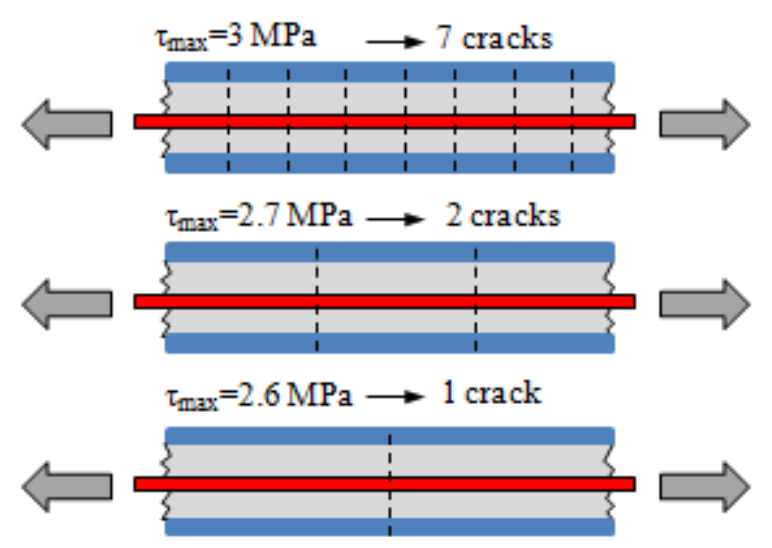

Fig. 16. Procedure followed for obtaining the FRP critical ratio. 


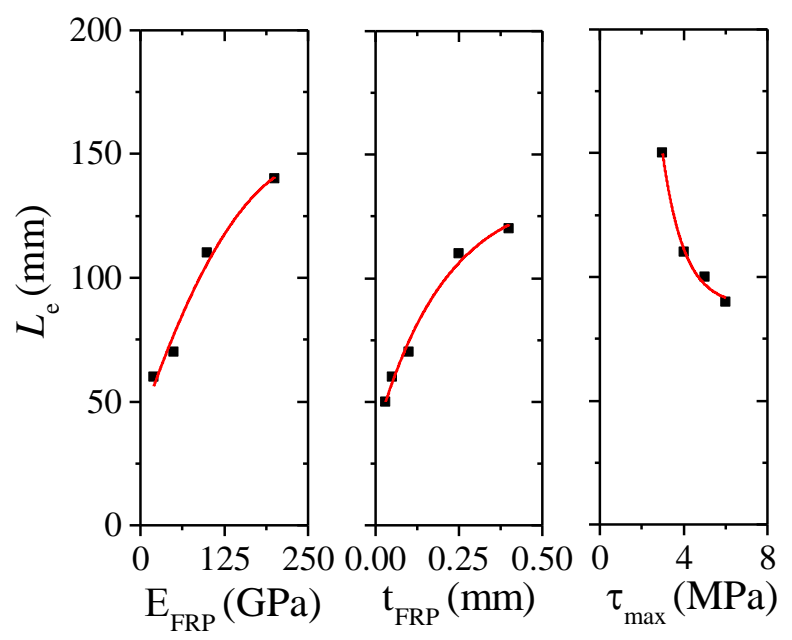

Fig. 17. Parametric study on FRP effective bond length. 




(a)

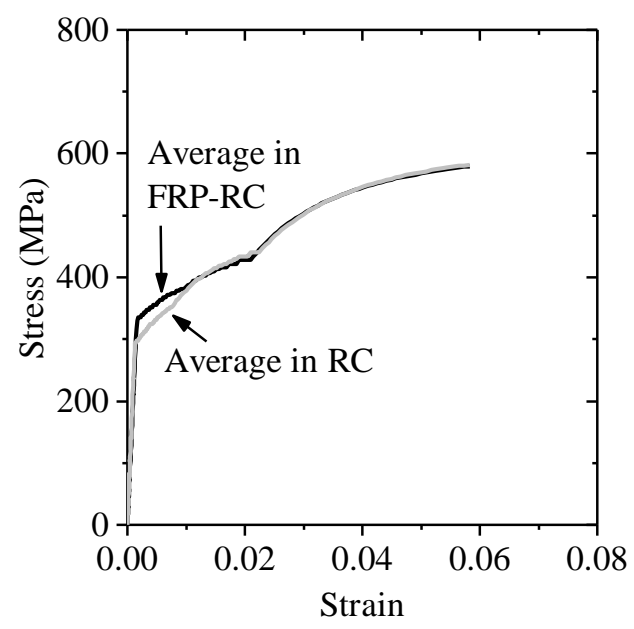

(b)

Fig. 18. Average response of reinforcing bars in: (a) RC elements; (b) FRP-strengthened RC elements. 


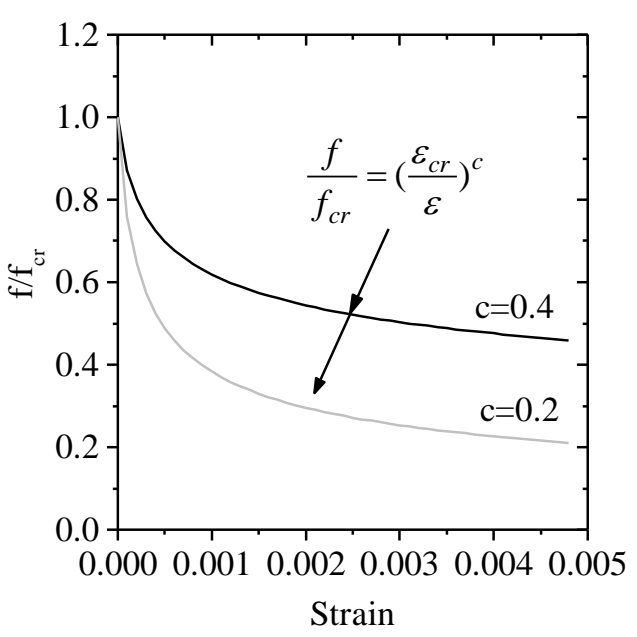

(a)

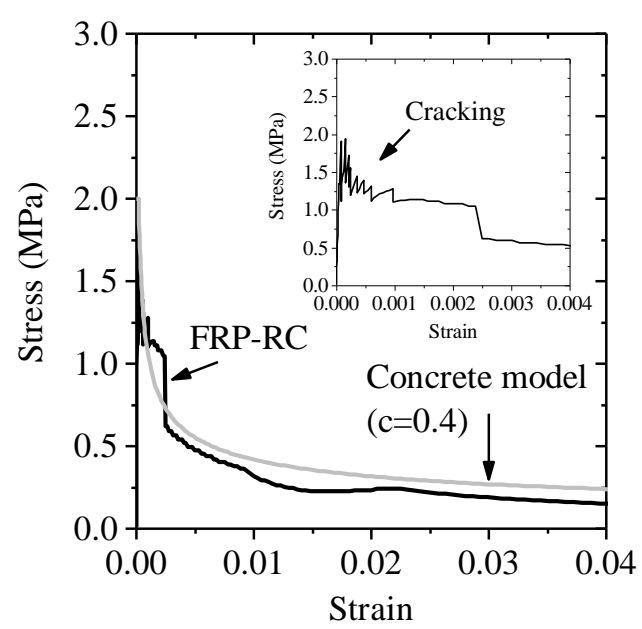

(b)

Fig. 19. Tension stiffening model for: (a) RC elements [53]; (b) FRP-strengthened RC elements. 


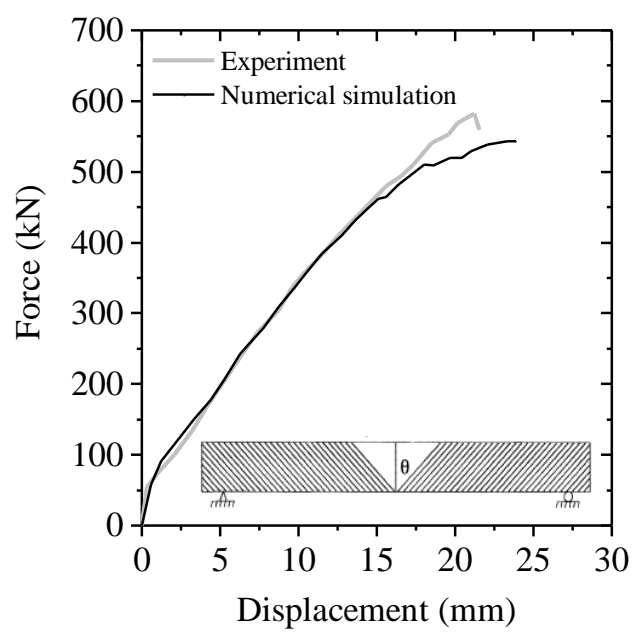

(a)

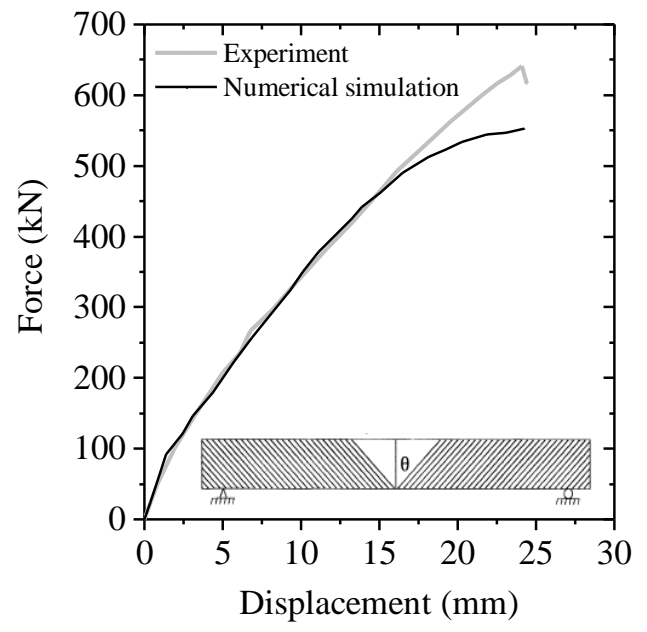

(b)

Fig. 20. Experimental and numerical response of FRP-strengthened RC beams: (a) RC1; (b) C-5. 